\title{
Ações de divulgação e popularização das Ciências Exatas via ambientes virtuais e espaços não formais de educação ${ }^{+*}$
}

\author{
Carlos Coimbra-Araujo ${ }^{\text {** }}$ \\ Arthur Bergold ${ }^{\text {*** }}$ \\ Danilene Berticelli ${ }^{3 * * *}$ \\ Geocris Santos ${ }^{4 * * * *}$ \\ Marcos Schreiner ${ }^{\text {*** }}$ \\ Helio Monte-Alto ${ }^{6 * * *}$ \\ Raquel Speck ${ }^{7 * * *}$ \\ Gabriela Ferreira ${ }^{8^{* *}}$ \\ Camila Tonezer ${ }^{9 * * *}$ \\ Isac Rosset ${ }^{10 * * *}$ \\ Roberta Bartelmebs ${ }^{11 * *}$ \\ ${ }^{* *}$ Universidade Federal do Paraná - Curitiba - PR \\ *** Universidade Federal do Paraná - Campus Palotina - PR \\ **** Universidade Federal do Paraná - Campus Pato Branco - PR
}

\section{Resumo}

Por diversas razões, as Ciências Exatas têm se mostrado como uma das áreas do conhecimento científico que mais demandam ações em espaços não formais de ensino. Um dos principais motivos reside no fato de que a Matemática, a Física, a Química e a Astronomia serem tradicionalmente abordadas, dentro do ambiente escolar e no currículo formal, desvinculadas da realidade dos estudantes, sendo muitas vezes vistas como um conjunto de princípios inflexíveis e incompreensíveis. Dessa forma, o presente trabalho revisa os principais problemas que circundam o ensino das áreas científicas citadas, destinando destaque a ferramentas não formais para o ensino da Matemática, Física, Química, As-

\footnotetext{
+ Dissemination actions and the popularization of the Exact Sciences by virtual environments and non-formal spaces of education

* Recebido: dezembro de 2016. Aceito: maio de 2017.

${ }^{1}$ E-mail: carlos.coimbra@ufpr.br; ${ }^{2}$ E-mail: arthur.bergold@ufpr.br; ${ }^{3}$ E-mail: danilene@ufpr.br;

${ }^{4}$ E-mail: geocris.rodrigues@gmail.com; ${ }^{5}$ E-mail: marcosantonio@ufpr.br; ${ }^{6}$ E-mail: heliohenrique@ufpr.br;

${ }^{7}$ E-mail: raquel.speck@ufpr.br; ${ }^{8}$ E-mail: gabikaiana@ gmail.com; ${ }^{9}$ E-mail: ctonezer@gmail.com;

${ }^{10}$ E-mail: rosset@ufpr.br; ${ }^{11}$ E-mail: roberta.bartelmebs@ufpr.br
} 
tronomia e, em especial, aos modernos ambientes virtuais de ensino modelados pela Ciência da Computação. Outras dificuldades históricas que o ensino formal de Ciências Exatas tem sofrido no Brasil também são apresentadas e alguns dos principais recursos não formais buscados para complementar o currículo que usualmente é apresentado em sala de aula.

Palavras-chave: Popularização da Ciência; Divulgação Científica; Espaços Virtuais de Ensino; Ciências Exatas.

\begin{abstract}
For several reasons, the Exact Sciences have been shown as one of the areas of scientific knowledge that most demand actions in non-formal spaces of education. One of the main reasons lies in the fact that Mathematics, Physics, Chemistry and Astronomy are traditionally addressed, within the school environment and in the formal curriculum, unrelated to the student reality. Such subjects are often seen as a set of inflexible and incomprehensible principles. In this aspect, the present work reviews the main problems surrounding the teaching of the mentioned scientific areas, highlighting non-formal tools for the teaching of Mathematics, Physics, Chemistry, Astronomy and, in particular, the modern virtual environments of teaching modeled by Computing Science. Other historical difficulties that the formal education of Exact Sciences has suffered in Brazil are also presented, as well some of the main nonformal resources sought to complement the curriculum that is usually presented in the classroom.
\end{abstract}

Keywords: Popularization of Science; Scientific Dissemination; Teaching in Virtual Environments; Exact Sciences.

\title{
I. Introdução
}

A divulgação científica pode ser entendida como "o uso de processos e recursos técnicos para a comunicação da informação científica e tecnológica ao público em geral” (BUENO, 1984, p. 134). Ela se caracteriza como uma sequência de ações ocorridas dentro das diversas ciências básicas ou aplicadas, executadas no âmbito de escolas, instituições de ensino ou pesquisa, museus e centros de ciência, cuja principal produção científica se notabiliza no âmbito de exposições, palestras, encenações teatrais, filmes, documentários, livros, artigos em revistas ou jornais, entre outros (ZIMMERMANN, 2012). Professores, cientistas, jornalistas, comunicadores, divulgadores e estudantes de graduação das licenciaturas ou dos bacharelados 
são geralmente os mediadores das ações propostas. Outro termo ainda comumente utilizado para expressar o que acima foi exposto é o de "popularização da ciência". Popularização da ciência pode ser entendida, segundo Germano e Kulesza (2007), como a ampliação do conceito de divulgação científica, já que acrescenta a problematização da comunicação ciência/público baseada nos interesses e nas necessidades sociais coletivas.

Seguindo-se as linhas de pesquisa que buscam o resgate da dimensão social da educação em ciências, um ponto a se considerar é a importância da leitura do mundo pelos educandos, bem como a disponibilidade para o diálogo entre educadores-educandos sobre os conteúdos científicos que venham a contribuir para a mudança da realidade social (FREIRE, 1996). Nesse sentido, divulgar ciência para aqueles que têm acesso à educação de qualidade já é tarefa considerada relativamente complexa, tornando-se ainda mais singular quando considerados segmentos da população detentores de fragilidade econômica ou desfavorecimento social. Conforme pontua e questiona Queiroz (2012, p. 283),

\begin{abstract}
É o conhecimento científico um conhecimento para poucos? Quem tem acesso ao conhecimento produzido no âmbito das instituições de pesquisa científica? Quem financia essa produção? A serviço de quem estão a Ciência e a Tecnologia (C\&T)? Como elas são popularizadas? Exposições, feiras, semanas nacionais de $C \& T$ deixam claro para seus públicos as questões de cunho social suscitadas pelos processos de produção, validação e utilização da Ciência? Como seria uma Ciência solidária socialmente?
\end{abstract}

Nesse contexto, a convergência dos vários entendimentos sobre a problematização do assunto aponta para a reflexão de que um dos principais desafios atuais da divulgação científica é o de integrá-la coerentemente a processos dialógicos voltados à ampliação das possibilidades de inclusão social, promovendo o empoderamento das populações que não possuem o acesso a tais espaços como prática cultural. Dessa forma, o presente trabalho fará um recorte socioeducacional das principais atividades desempenhadas nos espaços não formais no intuito de proporcionar a divulgação, mas principalmente a popularização da ciência. Os espaços a serem abordados consistem basicamente naqueles definidos por entidades como o National Research Council (2009) (Conselho Nacional de Pesquisa dos Estados Unidos), que a partir de um amplo estudo sobre a educação não formal e as principais configurações para o aprendizado informal da ciência, citam os ambientes do cotidiano, os ambientes planejados e os programas fora da escola e para adultos.

O presente artigo, buscando explorar e revisar os pontos acima elencados, inicialmente discutirá o conceito de educação não formal e informal em ciências, para em seguida abordar ações específicas na área dos ambientes virtuais de ensino desenvolvidos pela Ciência da Computação, aspectos do ensino não formal e os espaços e recursos não formais no âmbito da Matemática, da Física, da Química e da Astronomia, que visem a divulgação e popularização científica. Breves considerações finais serão formuladas. Muito do conteúdo apresentado será voltado para vivências realizadas no Brasil, embora menções a experiências internacio- 
nais também possam ocorrer. O conteúdo bibliográfico citado nas seções a seguir, tais quais livros, artigos e demais produções, contém muitos aspectos atuais e de reflexão relacionados aos assuntos pautados, principalmente no que consta a experimentos e práticas descritas pelos autores citados, além da base teórica debatida na seção 2 que define e motiva o assunto. Em relação a aspectos práticos, temos, por exemplo, Sato et al. (2008) e Luz et al. (2013) que nos oferecem perspectivas conceituais e de aplicação sobre ambientes virtuais, principalmente no que se refere ao Coding Dojo, ambiente virtual em que participantes se reúnem para aprender programação. Da mesma forma, Martin (2012) estabelece um aprofundamento maior em relação ao uso de ambientes virtuais de aprendizagem, assim como é descrito em seus experimentos sobre cursos abertos massivos online (denominados pela sigla em inglês MOOC). Tais abordagens são discutidas na seção 3 do presente trabalho. Abordagens formais para a popularização da ciência que vão além do uso de computadores também são aqui trabalhadas, como por exemplo o uso de jogos como ferramenta não formal para o aprendizado da Matemática. Citamos por exemplo o artigo seminal de Perelman (1985), precursor do uso do jogo no ensino de Matemática. Ali há a exposição clara de quais tipos de jogos podem ser mais adequados para uso em sala de aula. No entanto, o desenvolvimento dessa abordagem, do ponto de vista de teóricos da educação tais quais Piaget, Vygotsky, Leontiev e Elkonin, foi analisado no texto da seção 4 sob o olhar de referências como Moura (1991) e Oliveira (2005). Do ponto de vista da denominada "transposição didática" na Matemática, também citamos Chevallard (1991), pioneiro do assunto. Experiências mais modernas dentro e fora da sala de aula, em nível nacional, no que concerne ao ensino não formal da Matemática, são abordadas em Bassanezzi (2008), Watanabe (2013) e Cardoso (2015). Astronomia, Física e Química também são abordadas respectivamente nas seções 5 e 6 , principalmente sob o ponto de vista das práticas lúdicas realizadas em museus de ciência e laboratórios didáticos. Atrações do tipo "show de ciências" e projetos universitários de extensão voltados para populações mais fragilizadas também são ilustrados. Para essas seções capturamos o relato de experiências de grande porte, atuais e bem-sucedidas, como as descritas, por exemplo, em Falcão e Lins de Barros (1999), Sfair et al. (2003), Montenegro et al. (2005), Arroio et al. (2006), Cazelli et al. (2008), Lupetti et al. (2009), Falcão (2012), Falcão et al. (2013).

\section{A educação informal e a não formal e os espaços não formais em ciências}

Partindo-se inicialmente da definição de Gohn (2006, p. 28),

A educação formal é aquela desenvolvida nas escolas, com conteúdos previamente demarcados; a informal como aquela que os indivíduos aprendem durante seu processo de socialização - na família, bairro, clube, amigos, etc., carregada de valores e cultura próprias, de pertencimento se sentimentos herdados; e a educação não formal é aquela que se aprende (...) via os processos de compartilhamento de experiências, principalmente em espaços e ações coletivas cotidianas. 
Nesse sentido, a educação não formal em ciências é definida como aquela que surge por meio da integração de experiências e elementos diversificados de aprendizagem em espaços extraescolares, ou mesmo nos escolares, por meio do uso do lúdico, da vivência visual ou da tátil, via instrumentos científicos, mídias computacionais ou situações do cotidiano, todas elas se configurando como ferramentas de ensino para o letramento científico (DE BOER, 2000; GOHN, 2006; GOHN, 2010). O processo de ensino e de aprendizagem, portanto, é amplo e não deve se limitar somente aos acontecimentos e aos objetivos da escola padrão. Dessa forma, a educação não formal tem o papel de apresentar complementaridades ao ensino formal.

Historicamente, a discussão sobre a necessidade de espaços não formais de ensino se origina possivelmente não só pela busca à complementaridade ao ensino formal, mas também como uma decorrência de reformas advindas da crítica à falta de qualidade das escolas (SAVIANI, 2009). A questão da qualidade no ensino regular também é apontada por Gadotti e Torres (1994) como fator crítico que prejudica o acesso dos indivíduos ao conjunto de bens e serviços disponíveis na sociedade, ou seja, que compromete o direito à cidadania. Além disso, o próprio direito ao ensino obrigatório, conforme disposto na legislação, o restringe a um determinado período de tempo, para o qual há idade própria para entrar e para sair. Nesse sentido, dado o seu caráter não regular, a educação não formal amplia e flexibiliza o tempo de aprendizado, não se limitando a uma determinada faixa etária ou a uma periodização.

Relacionando-se o ensino de ciências como objeto de estudo geral e, em particular, o ensino de ciências exatas, entende-se nitidamente que, no processo da construção do conhecimento científico, o ensino deve ir além de seus conteúdos disciplinares, evidenciando aspectos teóricos e práticos relacionados ao uso que os alunos farão desse conhecimento científico (PIETROCOLA, 1998). De acordo com Arruda et al. (2013), em situações não formais as pessoas aprendem ciências por livre escolha, de modo que a aprendizagem da ciência se dá no dia a dia do indivíduo e isso ocorre dentro do ambiente no qual está inserido. Vale enfatizar que o processo de aprendizagem dá-se de forma contínua por meios introduzidos no cotidiano da pessoa, mesmo que muitas vezes essa aprendizagem ocorra de forma equivocada.

Saindo do referencial do professor e adentrando o referencial do aluno, é possível ainda questionar quais são as fronteiras que validam uma alfabetização científica significativa e se a sala de aula é suficiente e necessária para a conquista desta validação. Não há dúvida de que ela é, de fato, necessária. No entanto, essa necessidade tem adquirido novas nuances à medida em que surgem novas linguagens e formatos, como a crescente prevalência da imagem sobre a palavra, além da consolidação de novas mídias, mormente as computacionais (KRESS et al., 2001; KRESS, 2003; PICCININI; MARTINS, 2004).

\section{Espaços não formais e ambientes virtuais modelados pela Ciência da Computação}

A emergência de novas tecnologias de informação e comunicação, impulsionada pelo avanço no desenvolvimento da Ciência da Computação, viabilizou nas últimas décadas a cria- 
ção de novos espaços de ensino e de aprendizagem. Estes espaços têm ampliado as possibilidades de acesso à informação e ao conhecimento, democratizando-os (MAIA; MATTAR, 2008). As mídias interativas tornam possível a mediação entre espaços formais e não formais de aprendizagem, na medida em que a educação escolar venha a beneficiar-se de suas potencialidades. Os ambientes virtuais de aprendizagem, por exemplo, cuja ênfase está colocada na aprendizagem colaborativa, podem ser utilizados de maneira complementar à educação regular, engendrando um processo educacional mais interativo, dinâmico e inclusivo. A aprendizagem é significativamente otimizada dentro de um contexto comunicacional e participativo, interativo e vivencial, em que os educandos são levados a pesquisar, a problematizar, a reconstruir e a ressignificar seus conhecimentos (MORAN; MASETTO; BEHRENS, 2013).

O ensino e aprendizagem de computação pode ser estimulado por meio de atividades como Coding Dojo, na qual os participantes se reúnem em um ambiente não formal para aprender e praticar programação (LUZ et al., 2013). A atividade se torna interessante pois estabelece um problema ou desafio que os participantes devem solucionar, cooperativamente, por meio de programação de computadores, o que acaba por estimular o espírito de equipe dos participantes. De fato, os principais princípios do Coding Dojo consistem na criação de um ambiente seguro que é colaborativo, inclusivo e não-competitivo, onde os usuários estão continuamente aprendendo (SATO et al., 2008).

Outra experiência de destaque são os cursos abertos massivos online (do inglês, massive open online courses, ou MOOC), que representam outra modalidade de espaço não formal de ensino que vem crescendo graças à pervasividade da Internet e à filosofia do livre compartilhamento de informação da Creative Commons (MARTIN, 2012). De acordo com McAuley et al. (2010),

Embora possa compartilhar de algumas das convenções de cursos tradicionais, tais como um cronograma predefinido e tópicos com assuntos semanais, um MOOC não cobra taxas nem pré-requisitos além de acesso à Internet e interesse, sem expectativa predefinida de participação, e sem acreditação formal.

A ideia se popularizou principalmente após a realização de um curso de Inteligência Artificial (IA) desenvolvido e conduzido pelos professores Sebastian Thrun e Peter Norvig da Universidade de Stanford, em 2011.

Martin (2012) relata a experiência de ter participado do curso de IA da Stanford em 2011, e ressalta o modo como os recursos tecnológicos da Web acabaram tornando a experiência muito próxima a um curso presencial conversacional. Durante aquele curso - e isto ainda se observa nos cursos MOOC atuais - houve muita atividade nos fóruns da Web. Os estudantes faziam perguntas nos fóruns e os professores logo gravavam vídeos chamados "office hours" para responder algumas das perguntas. Martin (2012) também relata o sucesso que teve ao utilizar o curso MOOC como um complemento às suas aulas presenciais. Estas acabaram se tornando o principal meio para discutir sobre o material disponibilizado pela Internet. Day e Fowley (2006) relatam uma experiência similar, constatando que, pelo fato de seus 
alunos já terem assistido às aulas de um MOOC previamente, puderam focar o limitado tempo de suas aulas presenciais em atividades de resolução de problemas que permitiram um melhor aproveitamento da aula por ter sido possível alcançar um entendimento mais profundo do assunto.

Outra atividade bem sucedida nesse sentido é a denominada "Khan Academy", uma academia de ensino de ciências por meio de um canal do YouTube, que tem uma filosofia própria de ensino online baseada em Salman Khan [vide, p.ex., Parslow (2012)], denominada "flipped classroom", ou "sala de aula invertida". Aqui, as aulas são online e curtas (cerca de 20 minutos) e seguem o paradigma de que não há sentido em se dividir os estudantes por classes. Cada estudante deve seguir o seu próprio ritmo e fazer o seu horário de aprendizado.

Alguns outros ambientes virtuais, além de softwares e ferramentas computacionais podem ser aplicadas em quaisquer das Ciências Exatas. Sistemas virtuais de gerenciamento de cursos encaixam-se nessa descrição, tais quais sistemas comerciais como o Blackboard, WebCT e TopClass, além de sistemas de acesso livre como o Moodle, o Ilias e o Claroline. Em particular, o Moodle, no Brasil é uma das ferramentas mais utilizadas em ações de Ensino à Distância $(\mathrm{EaD})$ de currículos universitários, do ensino médio, técnico e até mesmo do ensino fundamental (COLE, 2005; ABEGG et al., 2010; MOODLE, 2017). Ele é um sistema virtual de gerenciamento de cursos que auxilia profissionais do ensino a criar comunidades de aprendizado online, e cujo design tende a facilitar a criação de novos cursos e a adição ou reciclagem permanente de conteúdo. Nesse contexto, alguns autores, como Rice (2006) percebem que o Moodle e outros sistemas de gerenciamento de cursos tendem a ser uma forma autêntica de abordagem de pedagogia construtivista, nesse caso virtual.

Além do exposto, no decorrer das próximas seções citaremos vivências do ensino não formal e da popularização que utilizam não só as ferramentas presenciais mais tradicionais, mas também ilustraremos aquelas que usam algumas ferramentas computacionais importantes em gamificação e outras estratégias, já que a colaboração pode acontecer não necessariamente na forma virtual e um grupo de indivíduos pode utilizar um software conjuntamente fora de um ambiente formal de ensino e se apropriar de um conhecimento significativo.

\section{Importância, experiências e estratégias no ensino não formal de Matemática}

As preocupações com o ensino e aprendizagem da matemática, tão fortemente ligadas ao presente e às projeções para o futuro, (...), têm descuidado da dimensão histórica. Esse descuido, não raro, faz subtrair à análise e às propostas de transformações as heranças que todos os ofícios carregam consigo. Sem ter presente essa dimensão histórica, os projetos de melhoria do ensino de matemática tendem ao fracasso.

Essa citação de Valente (2008, p. 12) dispõe sobre a importância do conhecimento da história da Matemática como essencial para que se compreenda suas transformações e mudanças ocorridas ao longo do tempo. 
As necessidades de ensino e aprendizagem da Matemática como disciplina, de acordo com a história da educação matemática, surgiram no Brasil em meados do século XVII, quando a Coroa Portuguesa, preocupada com a defesa da Colônia, decide impulsionar a formação de militares em terras do além-mar (VALENTE, 2008).

Hoje as finalidades e o enfoque da Matemática no país são diversas. Numa sociedade que muda numa velocidade surpreendente, mudam também as demandas e com isso a necessidade de preparação dos alunos para a mobilidade. Nesse sentido o ensino e aprendizagem de matemática podem contribuir para essa preparação. De acordo com o NCSM (The National Council on Supervision of Mathematics) cuja discussão deu origem ao documento "Basic Mathematical Skills for the 21st Century”, o ensino de matemática deve proporcionar o desenvolvimento de habilidades básicas necessárias aos estudantes durante sua maioridade responsável. O documento indica como "básicas" habilidades que são necessárias para que "restem abertas ao indivíduo tanto as portas para o emprego quanto para uma educação posterior". Lorenzato e Vila (1993), que discutem o documento, indicam que os estudantes devem revelar uma perfeita compreensão dos conceitos e princípios matemáticos, raciocinar claramente e comunicar efetivamente ideias matemática, reconhecer aplicações matemáticas no mundo ao seu redor e abordar problemas matemáticos com segurança. O NCSM identifica doze áreas de competência que todos os alunos devem apresentar em Matemática: resolução de problemas, comunicação de ideias matemáticas, raciocínio matemático, aplicação da Matemática à vida quotidiana, percepção de que a resposta é razoável, estimação, habilidades apropriadas de cálculo, pensamento algébrico, medidas, geometria, probabilidade e estatística.

É neste contexto que se caracterizam os diferentes ambientes de aprendizagem e a diversificação das práticas pedagógicas. Levar o aluno a gostar de Matemática é um dos grandes desejos dos professores, talvez o principal. "Acreditamos que esse gosto se desenvolve com mais facilidade quando é movido por interesses e estímulos externos à Matemática, vindos do "mundo real"” (BASSANEZI, 2010, p. 15). Os espaços educativos não formais podem caracterizar esse "mundo real" por permitir trabalhos que se desenvolvem de forma lúdica e interativa, favorecendo ao aluno o contato com materiais, peças, relíquias, pinturas, esculturas, além dos objetos que na sala de aula poderiam não ser visualizados ou apenas visualizados por meio virtual. Nesse sentido, cabe ao professor, com o material e os espaços que lhe são disponíveis, oportunizar situações que possibilitem a aprendizagem em ambientes fora do espaço da sala de aula, estimulando a participação dos alunos, de forma descontraída, sem cobranças, onde a curiosidade é constantemente alimentada.

Aprofundando essa análise, cite-se que o caso da Matemática é intrinsecamente sui generis, pois é uma das ciências exatas que mais demandam tratamentos não formais, por várias razões. De acordo com D’Ambrósio (1989, p. 1), “primeiramente, observa-se que os alunos passam a acreditar que a aprendizagem da matemática se dá por meio de um acúmulo de fórmulas e algoritmos". Na sequência, segundo esse mesmo autor, cria-se a ideia de que fazer matemática é seguir a aplicação de regras, que foram transmitidas pelo professor, des- 
vinculando-se assim, a Matemática dos problemas do cotidiano. Dessa forma, os alunos passam a considerar a Matemática como assunto incontestável, algo que não se pode duvidar ou questionar. Como consequências diretas, passa-se a supervalorizar o potencial da Matemática formal, desvinculando o conhecimento matemático de situações reais e, por não terem oportunidade de externar sua compreensão sobre os conteúdos, muitos alunos acabam perdendo sua autoconfiança no aprendizado da Matemática. Outro ponto observado por Freedman (2011) é que as dificuldades na aprendizagem da Matemática por seus alunos os deixavam frustrados e sem motivação. Uma vez desestimulados, eles passaram a interpretar a Matemática como um conjunto incompreensível de procedimentos. Essa autora encontrou, em alguns estudos, a recomendação de que ter experiências com a Matemática antes do início da educação formal favorece o sucesso do aluno nos primeiros anos da escola, acreditando que a Matemática pode funcionar como ponto de ligação para promover e estabilizar relações entre escolas e museus de ciências. Nesse sentido, diversos ambientes não formais podem contribuir como espaço para o ensino da Matemática.

O ensino da Matemática pode ser fortemente enriquecido com a diversificação das práticas pedagógicas e pela interação entre os campos da Matemática com outros, evitando reproduzir modos de pensar estanques e fracionados. Uma das possibilidades é trabalhar a Matemática inserida no contexto das tecnologias de informação. $\mathrm{O}$ mundo de trabalho exige trabalhadores criativos e versáteis, capazes de entender o processo de trabalho como um todo, dotados de autonomia e iniciativa para resolver problemas em equipe e para utilizar diferentes tecnologias e linguagens. A Matemática pode contribuir à medida em que explora a resolução de problemas e a construção de estratégias, além de possibilitar novas formas de comunicar e conhecer.

Nessa vertente, uma das propostas mais difundidas para complementar o ensino formal de Matemática é o uso de jogos matemáticos. O jogo recebe de teóricos como Piaget, Vygotsky, Leontiev, Elkonin, entre outros, as contribuições para o seu aparecimento em propostas de ensino de Matemática (MOURA, 1991). Yakov Perelman é um dos grandes precursores do uso do jogo no ensino de Matemática, usando-o como possibilidade de explorar um determinado conceito e colocando-o para o aluno de forma lúdica (PERELMAN, 1985). Os quebra-cabeças, os quadrados mágicos, os problemas desafios, entre outros, enquadram-se nessas características do jogo como o instrumento lúdico para lidar com o conceito de ensino não formal de Matemática. Segundo uma visão piagetiana, que faz do sujeito o centro de todo o processo de busca do conhecimento, a manipulação dos jogos, com suas regras e seus conteúdos matemáticos, em seus aspectos cognitivos e relacionais, criam situações práticas que desafiam a criança a se organizar para resolver problemas (OLIVEIRA, 2005). Além disso, os jogos podem contribuir na formação das atitudes necessárias para a aprendizagem da Matemática de uma maneira geral, tais quais o enfrentamento de desafios, a busca de soluções, o desenvolvimento da crítica, da intuição, da criação de estratégias e da possibilidade de alterálos quando o resultado não é satisfatório. 
O uso de jogos matemáticos pode ocorrer tanto dentro da sala de aula como em espaços não formais especialmente direcionados para isso, como nos casos de museus e também de feiras. Tomando por referência o trabalho de Chevallard (1991) e seu conceito de transposição didática da Matemática, afirma-se que a Matemática não é apresentada nos museus em seu estado puro, destacando-se os processos de transformação que o conhecimento científico sofre ao ser exposto nesses locais. No entanto, mesmo diante das possíveis perdas que uma transposição possa acarretar, os museus de Matemática são um excelente espaço para se narrar e contextualizar a história da Matemática, por meio de figuras ilustrativas e textos didáticos, além de oferecer a oportunidade de contato com os já citados jogos matemáticos, oficinas de códigos e criptografia matemática (que oferece uma interface com a Ciência da Computação), ou mesmo ferramentas simples e criativas em que o público pode entrar em contato com a geometria, construindo poliedros de PVC, de palitos de churrasco, com canudos, com linhas e com diversos outros tipos de materiais. Alguns relatos no campo dos museus de Matemática podem ser vistos em Watanabe (2013) e Cardoso (2015), que fazem um estudo sobre os espaços não formais dedicados à Matemática no Brasil e na cidade de São Paulo.

Em complemento, a modelagem matemática também pode ser uma alternativa, um método científico ou uma estratégia de ensino-aprendizagem possível de ser ensinada em ambientes não formais. A modelagem matemática consiste "na arte de transformação de problemas da realidade em problemas matemáticos e resolvê-los interpretando suas soluções na linguagem do mundo real" (BASSANEZI, 2008, p. 16). A modelagem pressupõe multidisciplinaridade. Vai ao encontro das novas tendências que apontam para a remoção de fronteiras entre as diversas áreas de pesquisa. Para Bassanezi (2008) a modelagem pode ser utilizada como um instrumento de pesquisa, aliada a outras Ciências como a Física Teórica, a Química Teórica ou, por meio da representação matemática de fenômenos biológicos, na Biomatemática, ou ainda em outras áreas como a Engenharia. Além disso, a modelagem pode constituir uma estratégia de ensino-aprendizagem buscando desenvolver a criatividade matemática do aluno no sentido de torná-lo um modelador matemático quando se dedica ao estudo de alguma situação fenomenológica.

Algumas ferramentas computacionais podem ser citadas no auxílio ao ensino não formal e à popularização da Matemática. Por exemplo, dentre outros, o aplicativo livre GeoGebra foi desenvolvido para promover ilustrações temáticas interativas nas áreas do cálculo, da álgebra, da geometria e da estatística. O aplicativo foi criado na Universidade de Salzburgo e desenvolvido no Instituto de Educação da Universidade de Cambridge e já ganhou diversos prêmios do setor educacional, sendo atualmente usado em diversos países, contando até mesmo com conferências específicas sobre o assunto (NASCIMENTO, 2012). Aulas online em diversas línguas são oferecidas no website do software e com ele muitos profissionais do ensino têm mensurado o nível de aprendizado matemático de estudantes, bem como o potencial de retenção de conteúdo (REIS, 2010). O aplicativo conta também com a possibilidade de 
estudantes aprenderem o significado das conjecturas matemáticas e maneiras efetivas de como provar teoremas de maneira intuitiva.

\section{Astronomia}

Uma das Ciências Exatas com maior destaque e melhores resultados na área de abordagens não formais é a Astronomia. Em especial, mesmo no currículo formal, ela é oferecida já nas séries iniciais. No entanto, as crianças aprendem no máximo o nome dos planetas e algumas informações sobre o Sol e a Lua. Apenas aquelas que participam de iniciativas como a Olimpíada Brasileira de Astronomia e Astronáutica (OBA) acabam conhecendo outros aspectos, como o conhecimento de estrelas, constelações, galáxias e nebulosas. Além disso, o saber científico ensinado em sala de aula é desvinculado do fantástico laboratório astronômico disponível a todo momento, i.e., o próprio céu noturno.

Nesse sentido, para o desenvolvimento de atividades de popularização da Astronomia não é necessário estar exatamente em um museu ou um espaço exclusivamente dedicado ao assunto, embora planetários e observatórios didáticos com telescópios de várias magnitudes enriqueçam positivamente as visitas guiadas e as mediações em Astronomia. Atividades com conteúdo expositivo e observacional a olho nu podem resgatar, por exemplo, a importância dos saberes dos povos da antiguidade (p.ex. tribos indígenas brasileiras) e sua precisão na previsão de eventos astronômicos e atmosféricos.

Além disso, oficinas de foguetes, para a confecção de projéteis experimentais de pequena escala, oficinas de relógios do Sol ou mesmo oficinas de telescópios de PVC, também se enquadram como excelentes formas de motivar estudantes para o estudo da Astronomia e também para o desenvolvimento de suas habilidades no campo da tecnologia. A observação de planetas, da Lua e de nebulosas com telescópios expandem naturalmente o conhecimento do público-alvo sobre a riqueza do universo. A descrição de experiências nesse campo, com destaque para vivências no Museu de Astronomia e Ciências Afins do Rio de Janeiro (MAST) podem ser vistas, por exemplo, em Falcão e Lins de Barros (1999), Cazelli et al. (2008) e Falcão et al. (2013). A internet como espaço não formal para a divulgação da Astronomia também é discutida em Nascimento et al. (2007).

A observação do céu também pode ser acompanhada pela exploração de softwares de astronomia, como é o caso do Celestia e do Stellarium. Este último é um software de distribuição livre bastante difundido dentro e fora da academia que funciona como um simulador da esfera celeste, de alta resolução, que permite mostrar o céu em condições similares às reais, e com a presença dos diversos astros comumente observados em telescópio (planetas, satélites, estrelas, nebulosas, galáxias e até mesmo o posicionamento online de cometas, asteroides e eventos meteoroides). Segundo informações obtidas no wiki oficial do sistema (STELLARIUM, 2017), o software possui banco de imagens com mais de 600.000 estrelas, constelações ilustradas de onze culturas diferentes, catálogo de Messier completo, planetas e satélites do sistema solar e os principais cometas. Tal conteúdo torna o programa em ferramenta ilus- 
trativa muito rica, que logicamente não substitui o ensino de astronomia. Algumas abordagens deste aplicativo como catalisador de atividades de ensino em astronomia podem ser conferidas em Longhini e Menezes (2010), Soler e Leite (2012), Oliveira et al. (2017).

\section{Abordagens em Física e Química}

No contexto de museus, centros de ciência e exposições científicas (como feiras), a Física, a Astronomia e a Química encontraram nos espaços não formais um laboratório dinâmico e fértil para investigações na área de concepções alternativas, mapas conceituais, entre outros.

Assim como no caso da Matemática, os espaços não formais podem contribuir para dirimir medos e distanciamentos que existem entre estudantes e a ciência Física ou Química. Em muitos casos tanto a Física quanto a Química são trabalhados como um conjunto de informações definitivas, inalteráveis, não sujeitas a críticas ou discussões. Além disso, a sociedade em geral, muitas vezes de forma não consciente, reproduz a opinião caricatural de que físicos e químicos são "cientistas loucos", de que a Física é perigosa, é a ciência da "bomba atômica" e a Química pode produzir produtos perigosos e danosos à saúde. Tais opiniões, embora não sejam o ponto central que expliquem o distanciamento de alunos em relação à Física ou à Química, acabam por influenciar negativamente na relação ensino-aprendizagem de tais ciências.

Um aspecto fundamental da Física em espaços não formais de divulgação diz respeito às temáticas geralmente presentes em tais espaços. A Física Clássica, representada em experimentos expositivos de mecânica, eletricidade, magnetismo, ótica e termodinâmica, responde majoritariamente pela Física nos museus e centros de ciência. Apenas recentemente temas relativos à física moderna e contemporânea se fizeram presentes em alguns espaços de divulgação (FALCÃO, 2012).

Alguns exemplos em particular, na área da Física, podem ser citados: a Universidade Federal do Paraná destaca-se desde 1998 com o programa de extensão FiBra (Física: Brincando e Aprendendo) o qual procura integrar, em suas atividades de divulgação da Física, a motivação do aprendizado e a formação da comunidade acadêmica em geral. Neste projeto destacam-se o planetário móvel, telescópios, câmara de vácuo, gerador de Van Der Graaf, bicicleta geradora de energia e outros experimentos preparados com o intuito de proporcionar a interação do público com a ciência física (SFAIR et al., 2003). O FiBra tem a intenção de ser um projeto itinerante e parte de seu acervo e equipamentos são expostos em escolas de Curitiba ou de cidades interioranas do Paraná. O Instituto de Física da Universidade de São Paulo tem projeto semelhante, com materiais, equipamentos e escopos parecidos. Tais experimentos, dada a sua característica de mobilidade, podem ser apresentados em escolas, feiras de ciências, ou permanecerem in loco em exposições permanentes de museus de ciências. Podem-se encontrar ainda "Clubes de Física" em algumas instituições como o Centro de Divulgação Científica e Cultural (CDCC) da USP em São Carlos, dos colégios militares do Rio 
de Janeiro e de Santa Maria, bem como em algumas escolas públicas. Frequentemente esses clubes também estão associados à Astronomia.

Em relação à Química, como já exposto, também há diversos problemas no que concerne ao ensino formal em sala de aula, semelhantemente ao que ocorre com a Física. A compreensão dos conceitos de reação química e dos elementos químicos pode ser ilustrado tanto no laboratório de Química da escola (lembrando que muitas não o tem) como nos espaços não formais fora da escola. Por exemplo, pode-se aprender muitos conceitos de química fora da sala de aula como desde o ambiente familiar, em casa, durante o preparo dos alimentos ou na limpeza, quanto ao ar livre, na observação da formação das nuvens de chuva e da poluição. Grupos de ensino não formal de Química, muitos deles itinerantes, usam a ludicidade para ensinar química para pessoas de diferentes faixas etárias, por meio de experimentos com reações químicas que expõem cores, sons, "explosões" e outras sensações, o que é estimulante e, de certo modo, inovador, pois facilmente captura a atenção e o encantamento de visitantes. Outros projetos de educação não formal em química podem ser encontrados, como a tabela periódica interativa, Show da Química, jogos (como o super trunfo dos elementos), visitas a laboratórios de prestação de serviço na área de química, seminários realizados em comunidades, entre outros (ARROIO et al., 2006).

Dentro ainda do aspecto de divulgação científica em espaços não formais nas áreas de Química e Física, existem diversas ações que buscam o elo entre a ciência e a arte para a comunicação da ciência. Por meio do teatro, por exemplo, é possível ensinar e divulgar a ciência de forma mais envolvente, interativa e prazerosa, em espaços informais de educação (SILVEIRA et al., 2009). Essas ações acontecem, muitas vezes, dentro de eventos de divulgação científica, tais como nas feiras de ciências e em museus ou centros culturais das cidades. Oliveira e Stoltz (2010) discutem que a realização de atividades teatrais na escola como prática educativa motiva a aprendizagem, a interação social e a expressão individual dos sujeitos. E ainda pontua que o teatro é uma modalidade artística que privilegia o uso da linguagem e promove o desenvolvimento da imaginação e do pensamento generalizante. Como atividade coletiva, o teatro promove uma forma especial de interação e cooperação entre os sujeitos, motivando os alunos à aprendizagem e permitindo-lhes construir seu próprio conhecimento. Alguns artigos reportam que as atividades teatrais se iniciaram com Aristóteles (414 a.C), na Grécia. Esses artigos ainda destacam que para o pensador grego, o teatro tinha a qualidade de ensinar as pessoas a enxergarem além do discurso, além das aparências, a ver o que estava encoberto nas profundezas (OLIVEIRA; ZANETIC, 2004; MONTENEGRO et al., 2005).

Nesse cenário, podemos destacar pelas suas atividades no Brasil os grupos de teatro Seara da Ciência, da Universidade Federal do Ceará (UFC) e o grupo de teatro OUROBOROS do Departamento de Química da Universidade Federal de São Carlos, que discutem fenômenos de química, bioquímica cotidianos e história da química por meio de peças teatrais. Esses grupos se destacam por serem projetos de extensão de universidades federais do Brasil e pela participação ativa dos acadêmicos dos cursos relacionados (MONTENEGRO et al., 
2005; LUPETTI et al., 2009). Assim como essas ações, pode-se citar também várias outras com o mesmo propósito, como a Casa da Ciência e o Museu da Vida, no Rio de Janeiro, a Estação Ciência de São Paulo, e o Núcleo de Ciências da Universidade Federal do Espírito Santo, dentre outros.

No campo da Física, há várias iniciativas do mesmo tipo, no entanto com uma vertente maior para os jogos teatrais nas escolas de ensino básico, com o intuito de trazer novas formas de avaliação diferentes das tradicionais e deixar a disciplina de forma mais humanizada, buscando o princípio de que a história da ciência é construída a partir da história de pessoas (JÚDICE; DUTRA, 2001). Essa preocupação foi muito bem colocada por Oliveira (2005) ao se deparar com os questionamentos dos alunos: "Como o físico trabalha? Ele faz somente experiências? Quem escreve as teorias? Ele trabalha ou só estuda? No Brasil também se faz física?"

Em complemento, existe hoje no Brasil, nas áreas de Física e Astronomia, a COOPERATIVA PAULISTA DE TEATRO do Núcleo Arte Ciência no Palco, que traz várias peças cujo foco é a divulgação científica. Dentre as mais famosas está a peça Copenhagen, que descreve a convivência entre os físicos Niels Bohr e Werner Heisenberg, pais da física quântica. Nesse sentido, é válido notar que muitas das iniciativas do teatro de divulgação científica, como as descritas nas últimas linhas, não fazem parte da extensão universitária de Instituições Públicas de Ensino Superior. Dentro desse aspecto, espera-se que ações desse porte possam servir como exemplos para o desenvolvimento, dentro da academia, de projetos que envolvam o campo artístico, principalmente o teatro, como forma eficaz de prática da educação não formal em prol da divulgação e popularização das Ciências Exatas.

Do ponto de vista das ferramentas computacionais que podem ser utilizadas no desenvolvimento da popularização da Física e da Química, podemos citar por exemplo o Modellus e o projeto PhET (Physics Education Technology), este último desenvolvido pela Universidade do Colorado, EUA, e que contém dezenas de simulações computacionais interativas de sistemas físicos (de movimento de projéteis a indução de campo eletromagnético e kits de circuitos elétricos) e químicos, mas também algumas aplicações em matemática e biologia. Wieman et al. (2008) realizaram 250 entrevistas com estudantes que utilizaram simulações PhET, e observaram que esses estudantes consideravam as simulações como fontes de diversão e ao mesmo tempo de conhecimento, utilizando a ferramenta, de forma espontânea, por horas, comparando-a a um jogo de vídeo game. Pesquisas desse porte dão oportunidade de desenvolver o que hoje é denominado "gamificação", o aproveitamento lúdico de ferramentas computacionais (ou mesmo tradicionais) para o ensino de ciências [vide definições mais aprofundadas e um leque maior de exemplos em de Sousa Borges et al. (2014) e Oliveira et al. (2017)]. 


\section{Considerações finais}

O presente trabalho apresentou uma revisão sobre os principais aspectos relacionados à divulgação e popularização das ciências exatas usando-se espaços não formais de ensino. Foram realizados recortes sobre a problemática da educação não formal e a divulgação científica carreada via espaços não formais como os museus e as feiras de ciências. Abordou-se ainda visões sobre a atuação e papel de algumas mediações na popularização das ciências exatas.

Os espaços não formais possuem diversas qualidades de cunho dialógico entre público e ciência, por não serem restritos apenas aos limites da relação professor-aluno da sala de aula. Eles criam a possibilidade de que o aluno transcenda os objetivos propostos nas aulas convencionais nas escolas, que muitas vezes, possuem apenas o quadro negro e o livro didático como únicos instrumentos didáticos à disposição no espaço escolar. Os espaços não formais estimulam a complementaridade entre os saberes e permitem a aplicação de metodologias capazes de despertar em jovens, crianças e adultos e, em particular, nos alunos das escolas, novas opções de aprimoramento do conhecimento, de forma lúdica, participativa e criativa.

\section{Referências bibliográficas}

ABEGG, I.; DE BASTOS, F. P.; MÜLLER, F. M. Ensino-aprendizagem colaborativo mediado pelo wiki do Moodle. Educar em Revista, n. 38, p. 205-218, 2010.

ARROIO, A.; HONÓRIO, K. M.; WEBER, K. C.; HOMEM-DE-MELLO, P.; GAMBARDELLA, M. T. P.; SILVA, A. B. F. O Show da Química: motivando o interesse científico. Química Nova, 29, 1, 2006.

ARRUDA, S. M.; PASSOS, M. M.; PIZA, C. A. M; FELIX, R. A. B. O aprendizado científico no cotidiano. Ciência \& Educação, Bauru, v. 19, p. 481-498, 2013.

BASSANEZI, R.C. Ensino e aprendizagem com modelagem matemática: uma nova estratégia. 3.ed., $2^{a}$ reimpressão. São Paulo: Contexto, 2010.

BUENO, W. C. Jornalismo científico no Brasil: compromissos de uma prática dependente. Tese (Doutorado) - Escola de Comunicações e Artes da USP. São Paulo, 1984.

CARDOSO, V. C. Explorando os museus de ciências para o ensino da Matemática. In: XIV Conferência Interamericana de Educação Matemática. Anais... Chiapas, México, 2015.

CHEVALLARD, Y. La transposición didáctica: del saber sabio al saber enseñado. Buenos Aires: Aique, 1991.

CAZELli, S.; COIMBRA, C. A. Q.; VERGARA, M.; COSTA, A. F.; FALCÃO, D.; VALENTE, M. E. Mediando ciência e sociedade: o caso do Museu de Astronomia Ciências 
Afins. In: MASSARANI, L.; ALMEIDA, C. (Ed.). Workshop Sul-Americano \& Escola de Mediação em Museus e Centros de Ciência. Rio de Janeiro: Museu da Vida / Casa de Oswaldo Cruz / Fiocruz, 2008.

COLE, J. Using Moodle. Nova Iorque: O’Reilly, 2005.

D’AMBRÓSIO, U. Como ensinar matemática hoje? In: Temas \& Debates, Sociedade Brasileira de Educação Matemática, Ano II, nº 2, 1989.

DAY, J.; FOLEY, J. Evaluating a Web lecture intervention in a human-computer interaction course. IEEE Transactions on Education, v. 49, n. 4, 2006.

DE BOER, E. G. Scientific Literacy: another look at its historical and contemporary meanings and its relationship to Science Education Reform. Journal of Research in Science Teaching, v. 37, n 6, p. 582-601, 2000.

DE SOUSA BORGES, S.; DURELLI, V. H.; REIS, H. M.; ISOTANI, S. A systematic mapping on gamification applied to education. In: ANNUAL ACM SYMPOSIUM ON APPLIED COMPUTING, 29th, 2014. Proceedings... p. 216-222.

FALCÃO, D. A física em museus e centros de ciência. In: GARCIA, N. M. D.; HIGA, I.; ZIMMERMANN, E.; SILVA, C. C.; MARTINS, A. F. P. (Org.). A Pesquisa em Ensino de Física e a sala de aula - articulações necessárias. São Paulo: Livraria da Física Editora, 2012.

FALCÃO, D.; LINS DE BARROS, H. Estudo de impacto de estudantes que visitaram um exposição de astronomia. In: ENCONTRO NACIONAL DE PESQUISA EM EDUCAÇÃO EM CIÊNCIAS, 2, 1999, Valinhos, SP. Anais... Belo Horizonte - MG: ABRAPEC, 1999.

FALCÃO, D.; COIMBRA, C. A. Q.; CAZELli, S.; VALENTE, M. E. A. O Programa Educativo do Museu de Astronomia e Ciências Afins. Ensino Em Re-Vista, v. 20, n. 1, p. 193208, jan./jun. 2013.

FREEDMAN, A. Balancing the Equation: Strengthening Museum-School Partnerships Through Math. Partial Fulfillment. John F. Kennedy University, 2011.

FREIRE, P. A pedagogia da autonomia. São Paulo: Cortez, 1996.

GADOTTI, M.; TORRES, C. A. Educação Popular: Utopia Latino-Americana. São Paulo: Cortez Editora, 1994.

GERMANO, M.; KULESZA, W. Popularização da Ciência: uma revisão conceitual. Caderno Brasileiro de Ensino de Física, v. 24, n. 1, 2007. 
GOHN, M. G. Educação não-formal, participação da sociedade civil e estruturas colegiadas nas escolas. Ensaio: Avaliação e Políticas Públicas em Educação, Rio de Janeiro, v. 14, n. 50, p. 27-38, jan./mar., 2006.

GOHN, M.G. Educação não formal e o educador social: atuação no desenvolvimento de projetos sociais. São Paulo: Cortez Editora, 2010.

JÚDICE, R.; DUTRA, G. Física e Teatro: Uma parceria que deu certo! Física na Escola, v. 2, n. $1,2001$.

KRESS, G.; JEWITT, C.; OGBORN, J.; TSATSARELIS, C. Multimodal rhetorics of the science classroom. London: Continuum, 2001.

KRESS, G. Literacy in the new media age. London: Routledge, 2003.

LONGHINI, M. D.; MENEZES, L. D. D. Objeto virtual de aprendizagem no ensino de astronomia: algumas situações-problema propostas a partir do softare Stellarium. Caderno Brasileiro de Ensino de Física, v. 27, n. 3, p. 433-448, 2010.

LORENZATO, S; VILA, M. C. Século XXI: qual Matemática é recomendável? Revista Zetetiké, v. 41, nº 1, Ano I, 1993.

LUPETTI, K. O.; ZUIN, V. G. Ambientalização em um espaço não-formal de ensino: Núcleo OUROBOROS de divulgação Científica. In: ENCONTRO NACIONAL DE PESQUISA EM EDUCAÇÃO EM CIÊNCIAS, VII, 2009, Florianópolis, SC. Anais...

LUZ, R. M. B.; NETO, A. G. S. S.; NORONHA, R. V. Teaching TDD, the Coding Dojo Style. In: Advanced Learning Technologies (ICALT), 2013 IEEE 13th International Conference on. IEEE. p. 371-375, 2013.

MAIA, C.; MATTAR, J. ABC da EAD. 3 ed. São Paulo: Pearson Prentice, 2008.

MARTIN, F. G. Will massive open online courses change how we teach? Communications of the ACM, v. 55, n. 8, p. 26-28, 2012.

MCAULEY, A.; STEWART, B.; SIEMENS, G.; CORMIER, D. The MOOC Model for Digital Practice, 2010. Disponível em: <http://www.elearnspace.org/Articles/MOOC_Final.pdf>. Acesso em: 20 jun. 2015.

MONTENEGRO, B.; FREITAS, A. L. P.; MAGAlHÃES, P. J. C.; DOS SANTOS A. A.; VALE, M. R. O papel do teatro na divulgação científica: a experiência da Seara da Ciência. Ciência e Cultura, v. 57 n. 4, p. 31-32, São Paulo Oct./Dec. 2005.

MOODLE. Documentação sobre a ferramenta. Disponível em: <www.moodle.org >. Acesso em: 04 mai. 2017. 
MORAN, J. M; MASETTO, M. T.; BEHRENS, M. A. Novas tecnologias e mediação pedagógica. Campinas: Papirus, 2013.

MOURA, M. O. de. O jogo na educação matemática. In: O jogo e a construção do conhecimento. São Paulo: FDE, n.10, p. 45-53, 1991.

NASCIMENTO, C. M. P.; FALCÃO, D.; VALENTE, M. E. A. A Divulgação da Astronomia por Museus e Centros de Ciências por Meio da Internet. In: ENCONTRO NACIONAL DE PESQUISA EM EDUCAÇÃO EM CIÊNCIAS, VI, 2007, Florianópolis. Anais... Florianópolis: Abrapec, 2007.

NASCIMENTO, E. G. A. Proposta de uma nova aplicação como instrumento psicopedagógico na escola: o LABGG (Laboratório GeoGebra). In: CONFERENCIA LATINOAMERICANA DE GEOGEBRA, 2012. Actas... p. 448-455.

NATIONAL RESEARCH COUNCIL. Learning science in informal environment: people, places, and pursuits. Washington: National Academies Press, 2009.

OLIVEIRA, N. R.; ZANETIC, J. A presença do teatro no Ensino de Física. In: ENCONTRO NACIONAL DE PESQUISA EM ENSINO DE FÍSICA, IX, 2004. Disponível em: http://www.sbf1.sbfisica.org.br/eventos/epef/ix/atas/comunicacoes/co13-2.pdf. Acesso em: 18 ago. 2015.

OLIVEIRA, V. B. Jogos de Regras e a Resolução de Problemas. Petrópolis: VOZES, 2005.

OLIVEIRA, M. E. de; STOLTZ, T. Teatro na escola: considerações a partir de Vygotsky. Educar, Curitiba, n. 36, p. 77-93, 2010.

OLIVEIRA, V.; ARAUJO, I. S.; VEIT, E. A. Resolução de problemas abertos no ensino de física: uma revisão de literatura. Revista Brasileira de Ensino de Física, v. 39, n. 3, 2017.

PARSLOW, G. R. Multimedia in Biochemistry and Molecular Biology Education. Commentary: The Khan Academy and the Day-night Flipped Classroom. Biochemistry and Molecular Biology Education, v. 40, n. 5, p. 337-338, 2012.

PERELMAN, Y. Mathematics can be fun. Moscou: Mir, 1985.

PICCININI, C.; MARTINS, I. Comunicação multimodal na sala de aula de ciências: construindo sentidos com palavras e gestos. Ensaio Pesquisa em Educação em Ciências, v. 6, n. 1, p. 21-34, 2004.

PIETROCOLA, M. Limites da Abordagem Construtivista Processual. In: ENCONTRO DE PESQUISA EM ENSINO DE FÍSICA, 6, 1998, Florianópolis, SC. Florianópolis: Centro de Ciências da Educação da UFSC, 1998. 
QUEIROZ, G. A colaboração entre o museu e a escola: a pesquisa, o ensino e a popularização da Ciência. In: GARCIA, N. M. D.; HIGA, I.; ZIMMERMANN, E.; SILVA, C. C.; MARTINS, A. F. P. (Org.) A Pesquisa em Ensino de Física e a sala de aula: articulações necessárias. São Paulo: Livraria da Física Editora, 2012.

REIS, Z. A. Computer supported mathematics with Geogebra. Procedia Social and Behavioral Sciences, 9, p. 1449-1455, 2010.

RICE, W. H. Moodle e-learning course development. A complete guide to successful learning using Moodle. Nova Iorque: Packt Publishing, 2006.

SATO, D.; CORBUCCI, H.; BRAVO, M. Coding Dojo: An Environment for Learning and Sharing Agile Practices. In: AGILE, 08, 2008. p.459,464, 4-8.

SAVIANI, D. Formação de professores: aspectos históricos e teóricos do problema no contexto brasileiro. Revista Brasileira de Educação, v. 14, n. 40, p. 143-155, 2009.

SFAIR, R.; SPINA, F. A.; FERNANDES, A. S.; MARQUES JUNIOR, W.; KURUMOTO, N. K.; MAZZARO, I.; RODBARD, M. G. Texto eletrônico sobre os experimentos desenvolvidos no Projeto "Física: Brincando e Aprendendo - Fibra". In: Simpósio Nacional de Ensino de Física, XV, 2003, Curitiba. Atas... Curitiba: SBF, 2003.

SILVEIRA, A. F.; ATAÍDE, A. R. P.; FREIRE, M. F. F. Atividades lúdicas no ensino de ciências: uma adaptação metodológica através do teatro para comunicar a ciência a todos. Educar em Revista, 34, p. 251-262, 2009.

SOLER, D. R.; LEITE, C. Importância e justificativas para o ensino de astronomia: um olhar para as pesquisas da área. In: SIMPÓSIO NACIONAL DE EDUCAÇÃO EM ASTRONOMIA, II, 2012. p. 370-379.

STELLARIUM. Wiki do sistema. Disponível em: <www. stellarium.org/wiki>. Acesso em: 05 mai. 2017.

VALENTE, W. R. Quem somos nós, professores de matemática? Cadernos Cedes, Campinas, v. 28 n. 74, p. 11-23, jan.abr. 2008.

WAtanABE, M. T. A divulgação da Matemática nos Museus de Ciência. Pesquisa de Iniciação Científica. Santo André: UFABC, 2013.

WIEMAN, C. E.; ADAMS, W. K.; PERKINS, K. K. PhET: Simulations that enhance learning. Science, v. 322, p. 682-683, 2008.

ZIMMERMANN, E. Divulgação e comunicação da física em espaços não formais. In: GARCIA, N. M. D.; HIGA, I.; ZIMMERMANN, E.; SILVA, C. C.; MARTINS, A. F. P. (Org.). A 
Pesquisa em Ensino de Física e a sala de aula: articulações necessárias. São Paulo: Livraria da Física Editora, 2012. 